Published in Indoor Air Journal, vol. 15, pp. 27-32, 2005

\title{
Do Indoor Pollutants and Thermal Conditions in Schools Influence Student Performance? A Critical Review of the Literature
} Mark J. Mendell ${ }^{1 *}$

Garvin A. Heath ${ }^{2}$

${ }^{1}$ Lawrence Berkeley National Laboratory, Environmental Energy Technologies Division, Indoor Environment Department, 1 Cyclotron Road, MS 90-3058, Berkeley, CA 94720

${ }^{2}$ University of California Berkeley, Energy and Resources Group, 310 Barrows Hall \#3050, Berkeley, CA 94720

\section{* for correspondence:}

PH: $1-510-486-5762$

FX: 1-510-486-6658

E-M: mjmendell@lbl.gov

\begin{abstract}
To assess whether school environments can adversely affect academic performance, we review scientific evidence relating indoor pollutants and thermal conditions, in schools or other indoor environments, to human performance or attendance. We critically review evidence for direct associations between these aspects of indoor environmental quality (IEQ) and performance or attendance. Secondarily, we summarize, without critique, evidence on indirect connections potentially linking IEQ to performance or attendance. Regarding direct associations, little strongly designed research was available. Persuasive evidence links higher indoor concentrations of nitrogen dioxide to reduced school attendance, and suggestive evidence links low ventilation rates to reduced performance. Regarding indirect associations, many studies link indoor dampness and microbiologic pollutants (primarily in homes) to asthma exacerbations and respiratory infections, which in turn have been related to reduced performance and attendance. Also, much evidence links poor IEQ (e.g., low ventilation rate, excess moisture, or formaldehyde) with adverse health effects in children and adults and documents dampness problems and inadequate ventilation as common in schools. Overall, evidence suggests that poor IEQ in schools is common and adversely influences the performance and attendance of students, primarily through health effects from indoor pollutants. Evidence is available to justify (1) immediate actions to assess and improve IEQ in schools and (2) focused research to guide IEQ improvements in schools.
\end{abstract}




\title{
Practical implications:
}

There is more justification now for improving IEQ in schools to reduce health risks to students than to reduce performance or attendance risks. However, since IEQ-performance links are likely to operate largely through effects of IEQ on health, IEQ improvements that benefit the health of students are likely to have performance and attendance benefits as well. Immediate actions are warranted in schools to prevent dampness problems, inadequate ventilation, and excess indoor exposures to substances such as nitrogen dioxide and formaldehyde. Also, siting of new schools in areas with lower outdoor pollutant levels is preferable.

\section{Running Title:}

Review of School Environments and Performance

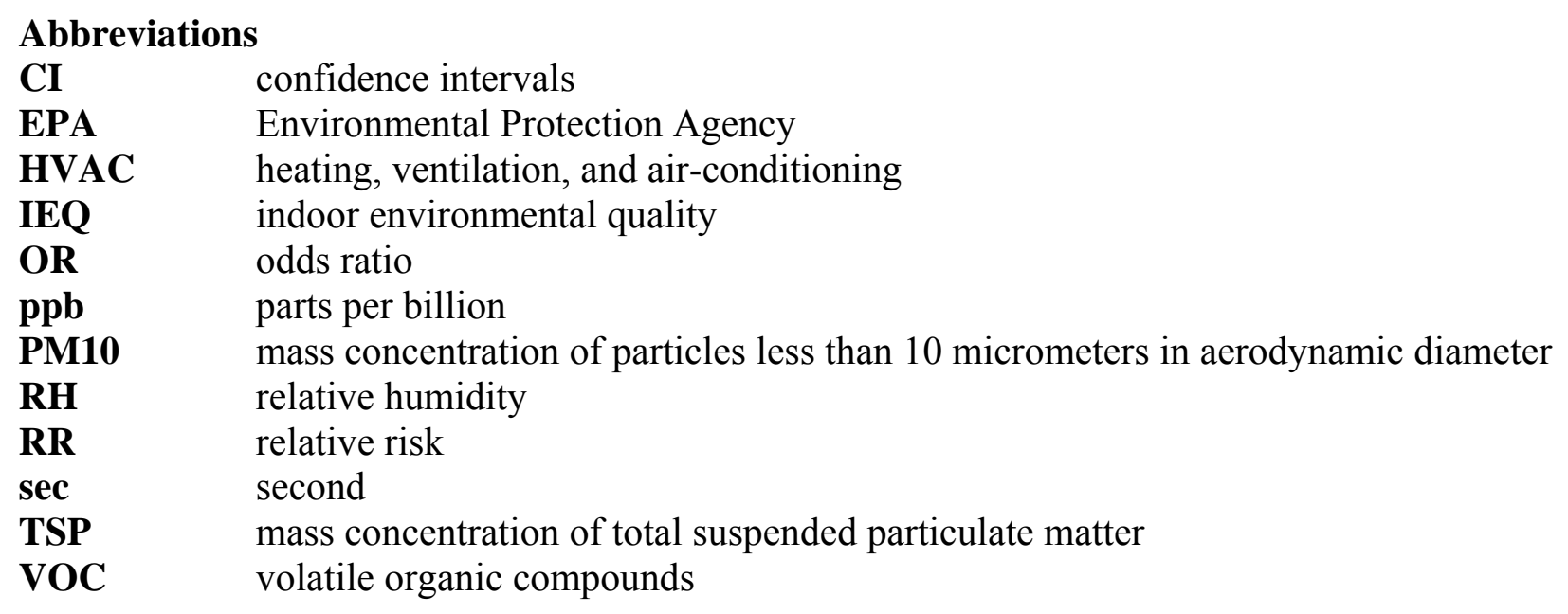

\author{
Key Words: \\ Indoor environment \\ Indoor air quality \\ Performance \\ Schools \\ Education \\ Children
}




\section{Introduction}

Public concern about adverse effects of indoor air has increased in recent decades, beginning with episodes during the 1970s in which occupants of residences and commercial and institutional buildings reported health problems associated with their buildings (Kreiss, 1989). Among the commonly reported complaints in these episodes have been eye and upper respiratory tract irritation, headache, fatigue, and lethargy, and breathing difficulties or asthma. Reporting of new episodes has continued unabated, particularly in commercial buildings and schools. Wider recognition of this problem has also produced concern that health problems from poor indoor environments may reduce the performance of occupants in buildings (Fisk, 2000; Mendell et al., 2002a).

Indoor environments in schools have been of particular public concern, for two primary reasons:

1) Schools, relative to other kinds of buildings, are seen as particularly likely to have environmental deficiencies because chronic shortages of funding contribute to inadequate operation and maintenance of facilities (U.S. General Accounting Office, 1995).

2) Children have greater susceptibility to some environmental pollutants than adults, because they breathe higher volumes of air relative to their body weights and their tissues and organs are actively growing (Landrigan, 1998; Faustman et al., 2000). Children also spend more time in school than in any indoor environment other than the home. Adverse environmental effects on the learning and performance of students in schools could have both immediate and lifelong consequences, for the students and for society.

There is little regulation in the U.S. regarding the indoor environments experienced by the approximately 50 million U.S. schoolchildren in over 90,000 schools. Few states regulate indoor school environments, and fewer still have minimum ventilation standards for schools. In the face of tight budgets, schools have little incentive or ability to protect children against poor indoor environments, particularly in the absence of clear documentation that inadequate indoor environments pose risks to performance, attendance, or health of students. Perhaps inevitably, these circumstances have led to environmental deficiencies in the nation's schools. The U.S. General Accounting Office reported in 1995 that $63 \%$ of students in the U.S. attended schools where one or more building features was in need of extensive repair, overhaul, or replacement, or that contained environmentally unsatisfactory conditions (U.S. General Accounting Office, 1995). Almost 14 million students attended school in buildings considered below standard or dangerous (U.S. General Accounting Office, 1995). These estimates considered only the obvious physical conditions, not the less apparent deficiencies in indoor environments such as inadequate ventilation found commonly in U.S. schools by other studies (e.g., Daisey et al. (2003)).

The primary objective of this paper is to review and summarize available scientific evidence on the relationship between selected aspects of indoor environments and the academic performance of students. (Figure 1 summarizes these connections). There are many ways, direct and indirect, in which aspects of indoor environments might influence the performance of building occupants. The term "indoor environmental quality" (IEQ) refers to indoor pollutants (including biological, chemical, or particulate pollutants) and thermal conditions (temperature and humidity), as well 
Figure 1. Primary associations reviewed.

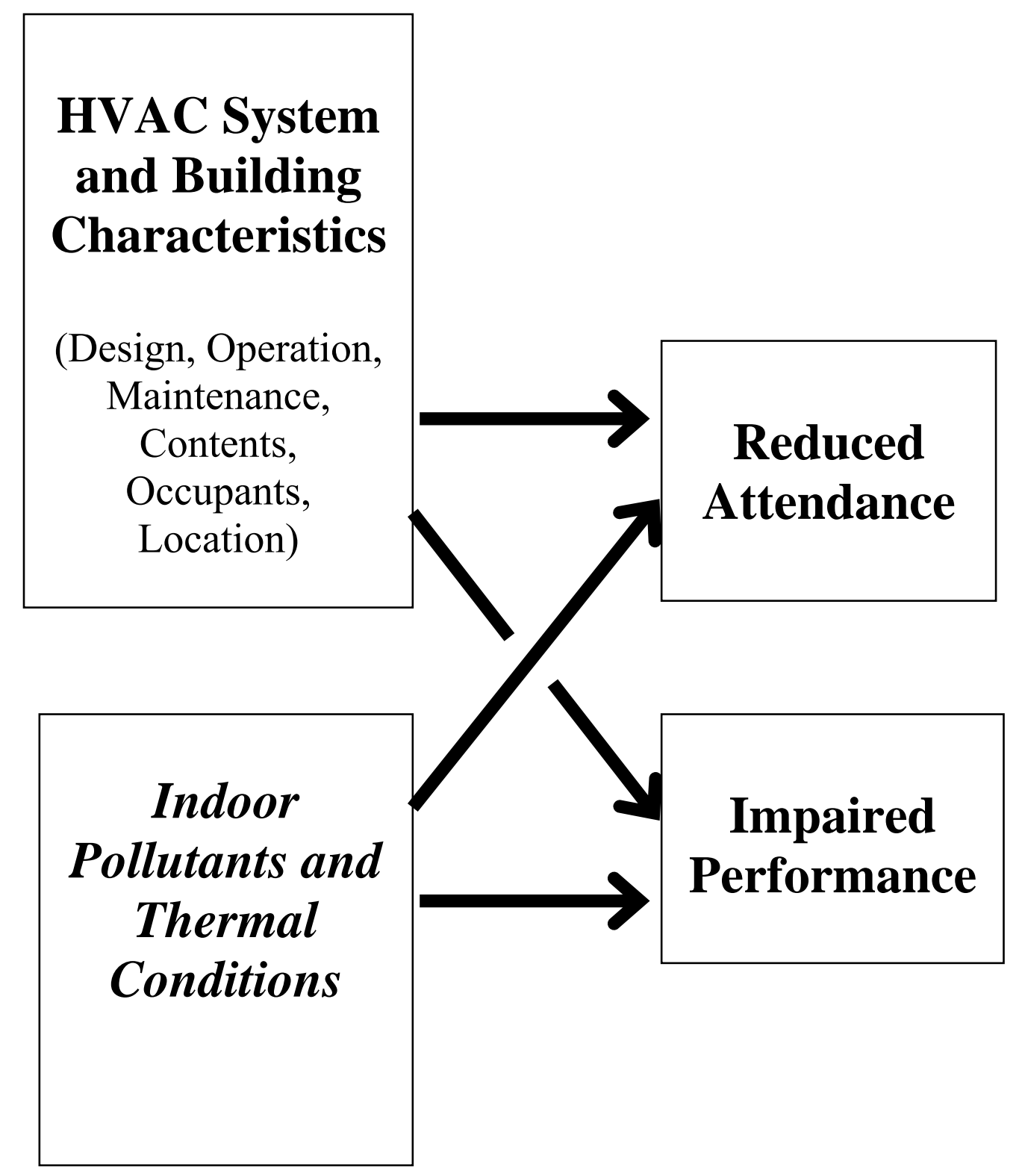


as noise, light, and odor (although the latter three are not considered in this review). Figure 2 shows a variety of hypothesized causal links underlying the associations in Figure 1, through which poor IEQ could impair students' performance or attendance. First, the characteristics and conditions of HVAC systems and buildings strongly influence IEQ. IEQ factors in turn could influence health outcomes of students (or teachers), which could influence students' performance directly or through effects on attendance (or through impaired teaching). IEQ factors might also influence performance through discomfort or distraction, or through thermal, visual, acoustic, or olfactory effects that reduce performance.

Reduced attendance may impair learning by decreasing class time for direct verbal and visual transfer of information from the teacher or by causing students to fall behind in their work. In addition, as school funding is often in part linked to attendance, reduced attendance could decrease school funding and thus impair a school's ability to provide a good learning environment, both physically and pedagogically.

Indoor environments in schools might cause health effects that directly impair concentration or memory - e.g., neurologic effects - or cause other health effects that indirectly affect learning. For instance, indoor pollutants might exacerbate diseases such as asthma or allergy that produce symptoms or absenteeism that in turn impair learning, or lead to use of medications that impair performance. Asthma is a principal cause of school absences from chronic illness, responsible for $20 \%$ of absences in elementary and high schools (Richards, 1986).

Public demand to improve the educational achievement of children in the US is strong. Sufficient documentation of the adverse effects of poor IEQ in schools on student performance, however, has not been available to motivate protective environmental guidelines in schools as a strategy to increase student achievement. The present review evaluates the strength and consistency of current direct evidence that indoor pollutants and thermal conditions in schools influence students' performance or attendance. Because little research has been reported on these relationships for children in schools, the review was expanded to include effects of other indoor settings on adults, assuming that influences of these other environments on adults have relevance to the influences of school environments on children. The review also goes beyond this to summarize evidence on other potential links that together connect IEQ and performance. Finally, the review highlights key gaps in our knowledge about IEQ and its effects in schools and suggests priority topics and strategies for research. 
Figure 2. Hypothesized causal links relating indoor environmental quality (IEQ) in schools to performance and attendance of students (Secondary associations summarized in this review are indicated by bold arrows; primary associations reviewed are shown in Figure 1. Noise and light are not included in this review.)

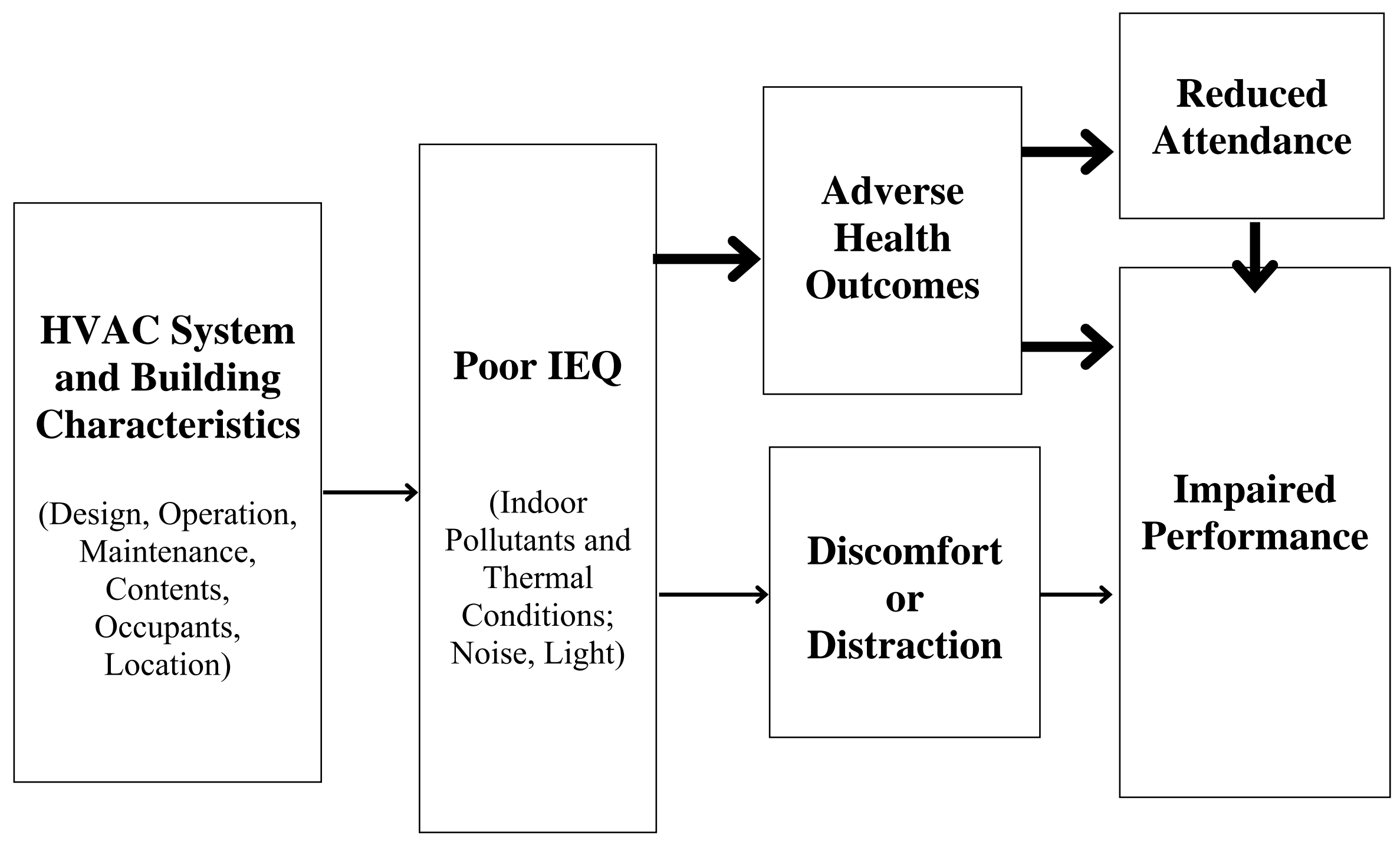




\section{Methods}

\section{Scope of review}

The central goal of this review is to assess evidence for relationships between IEQ within classroom environments in schools and the academic performance of students through high school. The review also includes findings on a broader range of indoor environments: potential adverse effects of school, university, day-care center, office, and home environments on their occupants. The specific tasks, motivations, aspects of the built environment, and other parameters could differ substantially between school and non-school environments and between children and adults. Potential similarities across these environments in the relationships between IEQ parameters and health, attendance and/or performance, however, warrant inclusion of these studies in this review.

The review also includes findings on other relationships that may constitute causal links between IEQ and the performance of building occupants (see Figure 2). These relationships include

- the influences of IEQ factors on health

- the influence of adverse health on performance or attendance

- the influence of absenteeism/attendance on performance

This review will not assess effects of IEQ on discomfort or distraction, and consequent effects on performance, except insofar as thermal conditions may operate through these effects to influence performance.

The human outcomes of primary interest in this review are performance and absenteeism. This review does not consider current controversies about the proper measurement of academic performance, but considers educational achievement tests and neurobehavioral performance tests to be relatively objective metrics of learning or performance that, whatever their limitations, are more accurate than subjective assessments of performance. Reduced attendance (i.e., absenteeism) could also influence performance at school (or work). Potential adverse health effects from indoor environments considered in this review include asthma and allergy; respiratory infections including colds, influenza, legionellosis, and sinus infections; lower or upper respiratory symptoms; and neurologic symptoms including headache, fatigue, or difficulty concentrating.

The environmental factors of primary interest in this review are considered in two categories: (1) measured IEQ factors, including pollutants and thermal conditions and (2) characteristics of heating, ventilation, and air-conditioning (HVAC) systems and buildings. Outdoor pollutants are secondarily included because characteristics of buildings, such as ventilation, design, and location, influence indoor exposures to pollutants entering from outdoors. The review excludes radon, lead, and asbestos, and also noise, light, and odor. The characteristics of HVAC systems and buildings considered here include pollution control practices such as ventilation or filtration that can reduce or dilute indoor contaminants, and the features or conditions of HVAC systems and buildings that can influence IEQ. 


\section{Search strategies}

We searched electronic databases of scientific publications through July 2003, including Medline/PubMed, Educational Resources Information Center (ERIC), Web of Science, and the American Society of Heating, Refrigerating and Air-conditioning Engineers (ASHRAE). Using a variety of search algorithms and combinations of key words, we sought publications related to indoor environments and either performance, absenteeism, or health, with separate searches for studies relating absenteeism to performance. In addition, we manually searched selected publications for relevant articles: the journal Indoor Air (previous 10 years); proceedings of the triennial International Conference on Indoor Air Quality and Climate ("Indoor Air '90" through "Indoor Air '02"); and the Healthy Buildings 1997 and 2000 conferences. We also used several unpublished reports or bibliographies (Daisey and Angell, 1998; Bayer et al., 2000). Finally, we reviewed other articles as appropriate to provide background information on current conditions in schools.

\section{Selection and evaluation of studies}

We identified and reviewed articles considered of primary relevance - those assessing direct associations between indoor environments and performance or attendance, in schools or other indoor environments - and critiqued their methodologies. We also identified and reviewed, without critique, articles considered of secondary relevance - those assessing relationships plausibly forming intermediate links between IEQ and performance or attendance (e.g., between IEQ and health, or attendance and performance). We include only peer-reviewed articles and articles published in proceedings of scientific conferences. We mention literature reviews found, without evaluating or summarizing them.

References of primary relevance included either measurement of indoor pollutant concentrations or thermal conditions or the characterization of HVAC systems or buildings, along with measures of performance or attendance. We critiqued these studies by evaluating the strength of study designs (including analysis and measurement methods) (see Cook and Campbell (1979), Rothman (1986), Mendell (1993)). Studies with the strongest designs - well-designed experiments, quasi-experiments (e.g., controlled field intervention studies), or prospective observational studies, with proper measurements and statistical analyses - were considered most persuasive. Findings from especially persuasive studies of particularly strong design are noted as such in the text and tables. This designation required all of the following: a good experimental, quasi-experimental, prospective cohort, or case-control design; appropriate measurement of risks and outcomes; adequate control, in the design or analysis, of major potential confounders; absence of other key study flaws such as substantial bias; and a sufficiently clear description of the study methods to assess the above features. This determination is finding-specific rather than study specific; for example, a strong experimental study may include less persuasive crosssectional findings as well.

Among studies of primary relevance, studies with weaker designs or analyses, such as those lacking statistical control for key potential confounding variables, were considered less persuasive. We excluded studies of particularly weak design, such as case studies, uncontrolled interventions, or crude comparisons of two groups unless they offered specific information of value. We also excluded studies using a doubly subjective measurement of performance (subjectively assessed performance impairment attributed to poor indoor environments) as an 
inherently biased version of an already weak measure. Unless stated otherwise, "significantly" increased risks reported here have p-values $<0.05$, and confidence intervals (CI) are 95\% CI.

We categorized overall evidence on the relationship of each specific aspect of IEQ to a human response in four categories: (a) persuasive evidence, sufficient to document a causal relationship - this designation required at least several strongly designed studies with consistent findings relating measured indoor exposures to objectively measured performance or attendance outcomes, with the overall findings making alternate explanations unlikely; (b) strongly suggestive evidence of a relationship but insufficient to document a causal relationship - this designation required at least several strongly designed studies with consistent findings, but not necessarily with measured exposures or objectively measured outcomes, or, in the absence of contrary results, one strongly designed study relating indoor exposures or risk factors to objectively measured outcomes; (c) suggestive evidence, requiring more than one reasonably well-designed study relating indoor exposures or risk factors to outcomes; or (d) sparse or no evidence or inconsistent evidence of a relationship.

Finally, the Discussion section synthesizes findings by considering the overall evidence available on specific relationships, emphasizing strong or consistent research, and then evaluating applicability of this evidence to children in schools. Research findings on children, whether in schools or non-school settings, will be considered directly applicable if the exposures or risks studied can also occur in schools.

\section{Results}

This review, from consideration of over 500 articles or reports, includes information on 30 references of primary relevance. Tables 1 and 2 describe key features of these 30 studies, the exposures or risk factors and outcomes studied, and the direction of the relevant findings. These research findings concern direct relationships, in schools or non-school indoor environments, between:

- pollutants and performance or attendance (Table 1);

- $\quad$ thermal conditions and performance or attendance (Table 1);

- characteristics of HVAC systems and performance or attendance (Table 2);

- characteristics of buildings and performance or attendance (Table 2).

Separate subsections of the tables describe studies of children and adults. Appendix 1, available as supplemental material at the journal's web-site, provides additional details on these 30 studies, including specific risks studied, magnitudes of effect or association, and methodological critiques.

Tables 1 and 2 are constructed so that, for consistency, all upward-pointing arrows signify increases in beneficial outcomes of either performance or attendance. Downward-pointing arrows signify decreases in beneficial outcomes. This required reversing, for some studies, both the outcome metric and the direction of finding reported; e.g., reported increases in absenteeism are presented here as decreases in attendance. 
Of the 30 references of primary relevance, 21 were from peer-reviewed studies and 15 had findings considered to be from strong study designs. Seven articles reported studies of children in school settings, of which two had strong study designs. The reviewed studies include findings from schools, day-care centers, universities, offices, and controlled laboratory settings. Studies assessed performance using educational achievement tests, neurobehavioral performance tests, psychological tests, simulated office tasks, electronically monitored job performance, or subjective assessments of performance. Studies assessed attendance using metrics of absenteeism, illness-related absenteeism, or respiratory illness-related absence. Some studies used objective attendance data from school or work records, while others used subjective recall of absence, which is more imprecise and susceptible to recall bias.

For studies of primary relevance, the Results section provides details on findings from all included studies conducted in schools regardless of study strength (because there were so few) and from all studies considered to be of strong design conducted in any indoor environment. Detailed presentation of findings and methods for others is provided in Appendix 1, available at the journal's web-site. (Thus, non-school studies of relatively weak design are summarized only in Tables 1 and 2 and in Appendix 1.) The last part of the Results section briefly summarizes published findings on relationships between outdoor pollutants and performance or attendance (with additional details provided in Appendix 1), IEQ and health, health and attendance or performance, and attendance and performance. 
Table 1. Findings ${ }^{\mathrm{a}}$ from research on direct associations between indoor pollutants or thermal conditions and performance or attendance

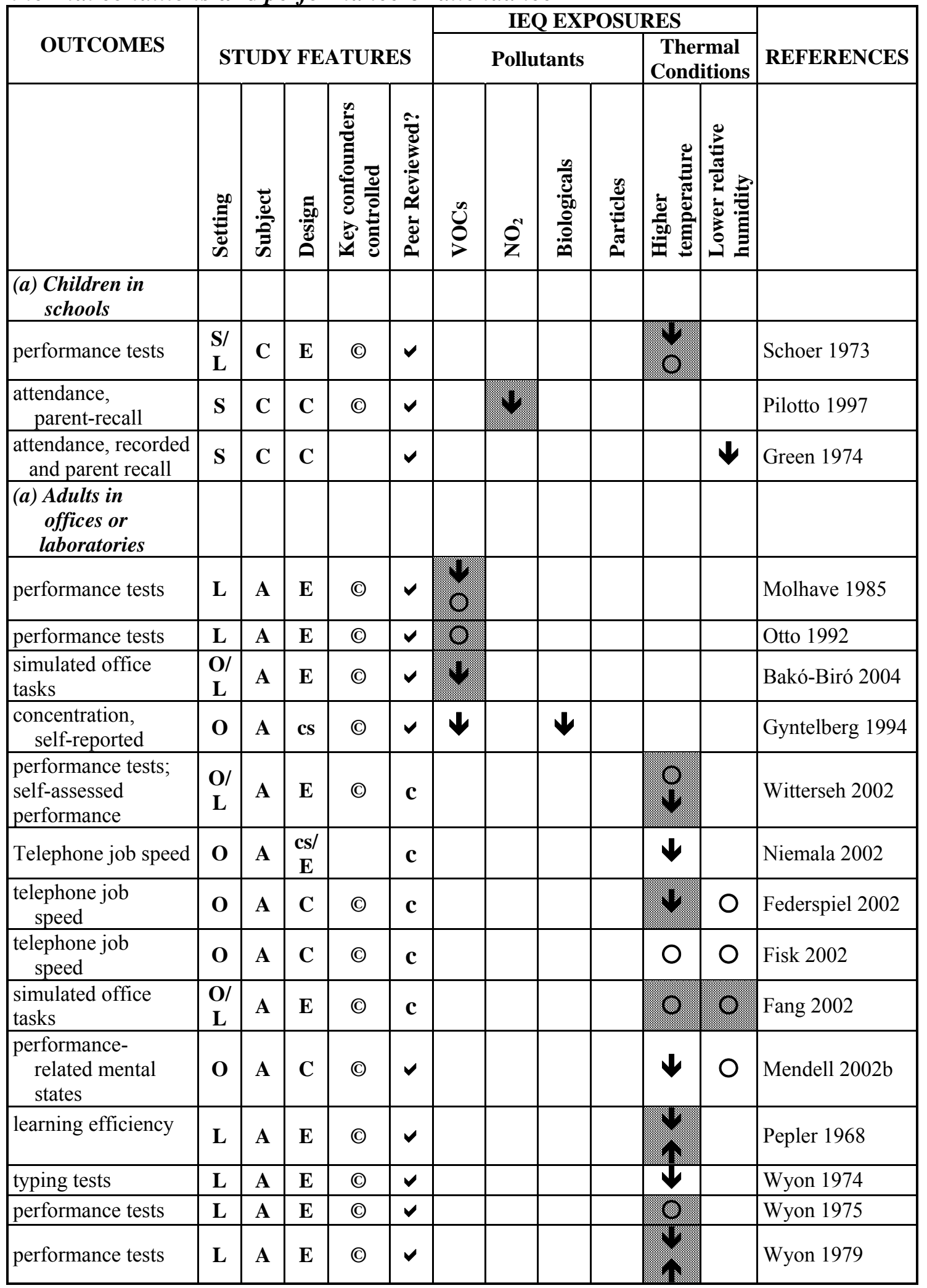




\section{LEGEND for Tables 1 and 2}

\section{Settings \\ S school (indoor or outdoor) \\ DC day care facility \\ O office or other non-school workplace \\ $\mathbf{R}$ residence \\ L laboratory \\ --- no specific setting}

\section{Subjects}

C children (age up to $\sim 16$ years)

A adults (age over $\sim 16$ years)

\section{$\underline{\text { Design }}$ \\ E experiment \\ qE quasi-experiment \\ C cohort (prospective \\ or retrospective) \\ cs cross-sectional}

\section{Control for Confounding}

(C) controlled or adjusted for key potential confounders

\section{Peer Review}

$\checkmark \quad$ peer reviewed

c in conference proceeding

\section{Relationships found}

\section{$\mathrm{O}$ no statistically significant or} noteworthy relationship statistically significant or noteworthy decrease in beneficial outcome ${ }^{\mathbf{a}}$
$\uparrow$ statistically significant or noteworthy increase in beneficial outcome ${ }^{\mathbf{a}}$

finding from study of strong design

a Arrows represent the direction of specific findings. Multiple arrows within a cell represent conflicting findings within a study. For consistency, upward-pointing arrows in these tables all represent positive effects. This required redefining outcomes for some reported studies; e.g., reported increases in illness absence, an adverse effect, are shown here as decreases in lack of illness absence. 


\section{Pollutants and performance or attendance Gases}

A strongly-designed laboratory experiment by Mølhave, et al. (1985) exposed self-identified "sensitive" adults to a mixture of 22 VOCs - a selected set of potential irritants common in indoor environments - at concentrations totaling 5 and $25 \mathrm{mg} / \mathrm{m}^{3}$. Exposures were associated with impaired memory on the digit span test ( $\mathrm{p}$-value $<0.01$, magnitude of change not reported), but not on the other performance test administered. Exposures were also associated with subjective reports of impaired ability to concentrate, dry mucous membranes, decreased air quality, and increased odor intensity. The VOC concentrations studied were much higher than generally found in indoor environments. Limitations in this study include the use of doses much higher than found in actual indoor environments and the likelihood that high doses of the irritant chemicals included negated the blind conditions. A later laboratory experiment by Otto et al. (1992), designed as a more rigorous replication of Mølhave et al. (1985) but in subjects without known sensitivities, failed to repeat the findings. Otto et al., however, did find increased subjectively assessed confusion and fatigue in subjects exposed to $25 \mathrm{mg} / \mathrm{m}^{3}$ of VOCs: confusion increased by 0.2 units from a mean level of $1.9(\mathrm{p}=0.03)$ and fatigue increased by 0.2 units from a mean level of $2.6(p=0.4)$. The use of sensitive subjects, lack of blind conditions, or other flaws in the research design of Mølhave et al. (1985), may explain the lack of replication of their objective findings by Otto et al. (1992).

A strongly designed experimental study reported by Bakó-Biró (2004) assessed effects of (chemical) emissions from 3-month old computers on the performance of simulated office work by adults in a controlled office laboratory. Presence of the computers increased time required for text processing by $9 \%$. Because measured concentrations of emitted chemicals were too low to explain the observed adverse effects, the authors suggested that other non-detected chemicals might cause these negative effects.

A strongly designed cohort study by Pilotto et al. (1997) on the effects of emissions from gas heaters in both school and home settings found significant, dose-response relations between indoor hourly peak concentrations of nitrogen dioxide greater than 80 parts per billion (ppb) and absences from school. In the high category of exposure (which was not above existing ambient standards), the adjusted absence rate increased from 0.014 to $0.024(\mathrm{p}=0.02)$, and the adjusted proportion absent increased from 0.47 to $0.63(\mathrm{p}=0.002)$. The OR (CI) for absenteeism at the higher exposure category was $1.92(1.13-3.25)$. The reported dose-response relation strengthens the evidence for a cause/effect relationship even at these low levels.

Biologic and particulate pollutants

No included studies assessed these relationships.

Thermal conditions (temperature and humidity) and performance or attendance Findings on the effects of temperature and humidity levels in buildings should be considered in conjunction with the findings, presented in the subsection below, on the presence of airconditioning/cooling systems and of humidification systems in buildings. A number of review articles are available on relationships between thermal conditions and performance or attendance 
(Green, 1985; Wyon, 1993; Levin, 1995; Wyon, 1996; Sensharma et al., 1998; Wyon, 2000; Pilcher et al., 2002).

Schoer and Schaffran (1973), in a set of well-designed experimental studies, assessed performance of students in a pair of classrooms set up as a laboratory, with one classroom cooled and one not. The study found a general advantage for performance tests in the cooled environment, with a consistent tendency for greater, statistically significant benefits for more complex performance tests. The number and variety of tests included in the three separate studies they reported precludes summary here of specific results. These were strongly designed studies with persuasive, although somewhat internally inconsistent, findings.

Witterseh et al. (2002) reported findings (briefly in a conference proceeding) from a strongly designed experiment with adults in a controlled office/laboratory setting. Temperature was among the conditions varied with other factors held constant. Subjects performed standardized performance tests and reported self-assessed performance and symptoms on a questionnaire. As temperature increased from $22^{\circ} \mathrm{C}$ to 26 and $30^{\circ} \mathrm{C}$, performance on tests did not change, although subjects reported decreased self-estimated performance $(\mathrm{p}<0.001)$, and increased difficulty thinking and concentrating (both $\mathrm{p}<0.01$ ).

Federspiel et al. (2002), in a conference proceeding, reported findings from a controlled, blinded quasi-experiment on ventilation rates and electronically monitored performance in a telephone call center. The study included real-time measurements of temperature (and relative humidity). Performance was assessed as the measured time for completing two separate tasks - talk time on the telephone and wrap-up time after each call. A multivariate analysis of individual performance averaged over worker shifts of approximately 8 hours, including temperatures from 21 to greater than $26^{\circ} \mathrm{C}$, showed effects only in the highest category of temperature $\left(>25.4^{\circ} \mathrm{C}\right)$, where both measures of performance decreased, including a slowing of wrap-up time by about 15\% (Federspiel et al., 2002).

Pepler and Warner (1968) reported, from an experimental study of learning efficiency among adults in a school laboratory, that as temperatures increased from $62^{\circ} \mathrm{F}$ to $80{ }^{\circ} \mathrm{F}$, speed of work decreased by $7 \%$, although error rates decreased by $17 \%$, all with $p \leq 0.05$. Insufficient information was provided to clarify various inconsistencies in the findings. Wyon (1975) reported, from an experimental chamber study in adult students, no differences in performance tests at different temperatures when subjects could adjust temperature as desired. Wyon et al. (1979) reported an experimental chamber study of the effects of rising temperatures between 20$29^{\circ} \mathrm{C}$ on mental performance in high school students. Although there was no consistent pattern of response on 10 aspects of performance, there was somewhat more evidence for adverse effects on performance from higher temperatures within the comfort range.

A strongly designed, controlled experimental trial on adults in a field laboratory by Fang et al. (2002) tested the effects of several temperature/RH combinations on the performance of simulated office tasks. Higher temperature/RH were not associated with changes in task performance relative to lower temperature/RH combinations. However, because subjects were encouraged to adjust their clothing as needed to maintain thermal equilibrium, and succeeded in 
doing this, the results may not be comparable to most other research findings in which this is not the case, or generalizable to real-world building environments.

Green (1974), from a prospective study of students in schools with or without humidification, reported consistent decreases in school absenteeism associated with indoor RH increased to between 20-40\%. Magnitudes of effect could not be easily summarized from this report, but absenteeism in the reported sub-studies decreased by 3-9\% for each percentage point increase in RH. Although the study design had limitations and statistical analyses were lacking, the flaws seem unlikely to have created this relationship spuriously.

\section{Characteristics of HVAC Systems and Performance or Attendance}

HVAC systems in buildings have two primary functions - to remove pollutants from indoor air and to control indoor thermal conditions. Specific HVAC features or operations can be related to one or both of these functions. Studies may assess aspects of HVAC systems by the simple presence or absence of a specific feature (e.g., humidification systems), by numeric specifications (e.g., efficiency of a particle filter), or by measured performance (e.g., flow rate of outdoor air delivered by ventilation).

\section{HVAC pollutant controls}

Myhrvold et al. (1996) reported from a quasi-experimental study in schools that higher indoor carbon dioxide concentrations (indicating less outdoor air ventilation) were associated with lower scores on a computerized test of reaction time. Magnitude of the effects was not reported, but the correlation adjusted only for age was $0.11(\mathrm{p}=0.009)$. A published graph suggested an apparent (unadjusted) dose-response relation: decreasing ventilation levels, corresponding to 0 999, 1000-1499, and 1500-4000 parts per million (ppm) of $\mathrm{CO}_{2}$, were associated with steadily reduced performance (mean performance indices of $-0.08,0.02$, and 0.13 , respectively, with more positive scores representing reduced performance). Despite the objective quality of the outcome measure, this report (Myhrvold et al., 1996) provided only very limited information in a brief, non-peer reviewed article and had numerous other substantial limitations.

A strongly designed experimental study (Wargocki et al., 2000) found lower ventilation rates linked to reduced performance among office occupants. Wargocki et al. (2000) reported that performance of four simulated office tasks improved monotonically with increasing ventilation rates, with a statistically significant trend for text typing $(\mathrm{p}<0.03)$, and similar patterns but larger $p$-values for addition $(p<0.06)$ and proof-reading $(p<0.16)$. On average, for each doubling of ventilation rate in the range between 3-30 L/sec per person, Wargocki et al. reported that work on specific office tasks increased from 1.1-2.1\%. In contrast, Fang et al. (2002), in a simpler comparison of two ventilation rates using the same controlled environment, found no differences in task performance, an unexpected finding attributed by the authors to the limited data collected on this contrast.

A well-designed and persuasive study in office buildings by Milton et al. (2000) found that ventilation rates substantially above current recommended levels were consistently associated with decreases of about one-third in short-term sick leave. The RR (CI) for short-term sick leave associated with lower ventilation rate (25 cfm/person vs. $50 \mathrm{cfm} /$ person) was $1.5(1.2-1.9)$. The authors suggested that this excess was likely to be due to respiratory disease and estimated that, 
Table 2. Findings ${ }^{\mathrm{a}}$ from primary research on relationships between $\mathrm{HVAC}$ system characteristics or building characteristics and performance or attendance

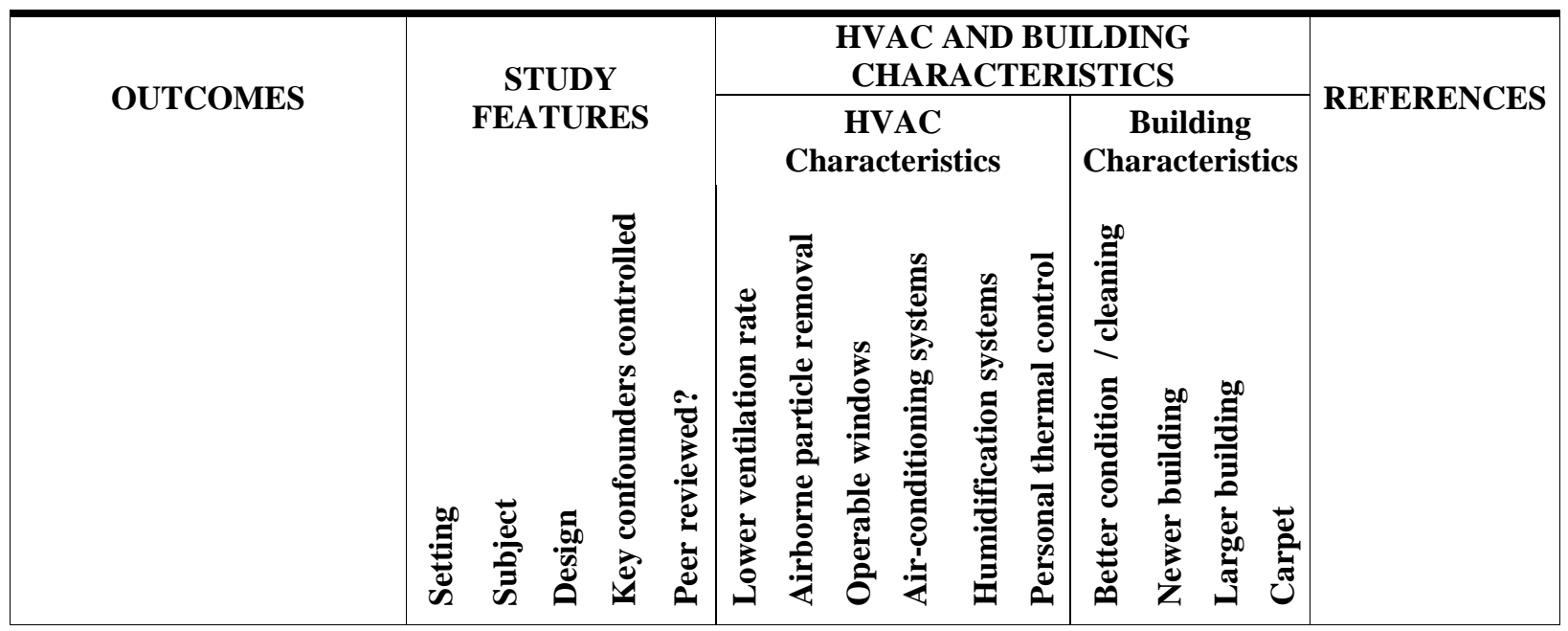

(a) Children in schools or day-care centers

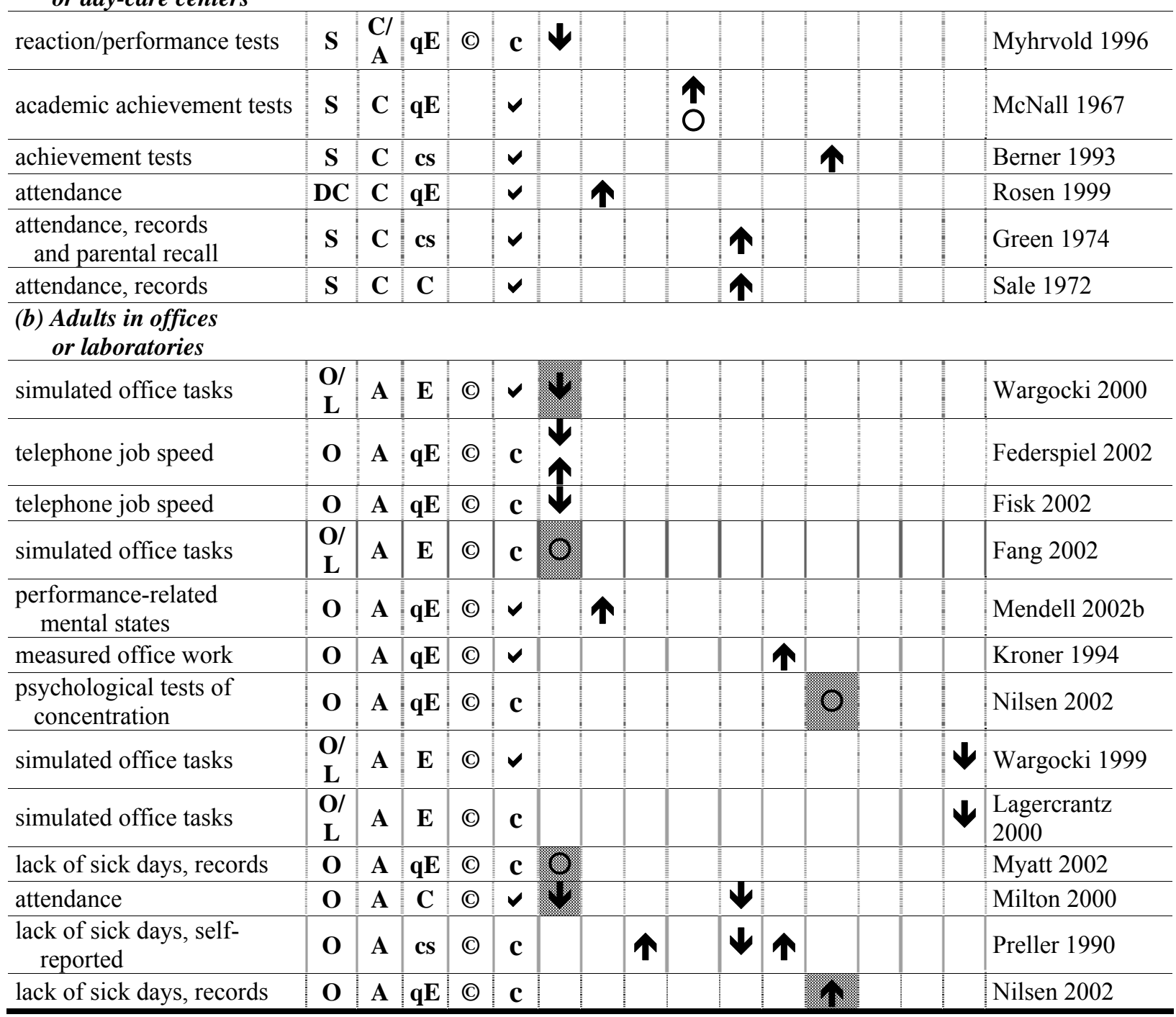


if this relationship were causal, as much as $35 \%$ of short-term sick leave in these offices could be prevented by raising ventilation rates above currently recommended rates. The study design and analyses were strong, despite the rough estimation of ventilation rates used.

In contrast, Myatt et al. (2002), in a crossover, quasi-experimental study of ventilation rates and sick leave among office workers in two buildings, found no association. All ventilation levels studied, however, were relatively high, with a maximum indoor-minus-outdoor $\mathrm{CO}_{2}$ differential of $250 \mathrm{ppm}$, and an average less than half the $700 \mathrm{ppm}$ maximum specified in ASHRAE standards.

Rosen and Richardson (1999) performed a quasi-experimental study in day-care centers that reduced indoor concentrations of small particles by $45-80 \%$ using negative ionization. They found the reduced concentration associated with significantly decreased absenteeism among children, but the study findings were not persuasive. The study, conducted in only two facilities, was small and not well-designed to separate effects of ionization from other possible explanations of findings. The $35-55 \%$ reductions in absenteeism associated with ionization the first year were not clearly different from a $36 \%$ reduction associated with a later period of no ionization.

$\underline{\text { HVAC thermal control systems }}$

No findings from studies of strong design were available on the relationships between HVAC thermal control systems and performance or attendance. McNall and Nevins (1967), in a quasiexperimental comparison between one air-conditioned school and several non-air-conditioned schools in Florida, found trends in favor of higher academic achievement in the air-conditioned school. Magnitude of findings cannot be easily summarized. The many limitations in design and analysis, particularly the inclusion of only one air-conditioned school, make these findings non-persuasive. This study also could not separate the presumably positive effects of cooler indoor temperatures in this hot-summer climate from other effects of the presence of the airconditioning systems. Numerous studies have found air-conditioning systems to be associated, even after statistical adjustment for differences in temperature, with adverse health effects in buildings, presumably due to production of contaminants (Mendell and Smith, 1990; Mendell, 1993; Seppanen and Fisk, 2002).

Green (1974) reported, from the previously described prospective study of schools, significantly lower absenteeism rates in humidified relative to non-humidified schools, both for 10 years overall (4.6 vs. $5.1 \%(\mathrm{p}<0.05))$ and for yearly pair-wise comparisons over the 10 years $(\mathrm{p}<0.01)$. This study had multiple limitations in design and analysis, particularly in failing to control for potential confounding, but these seem unlikely to explain the association found. Sale (1972), from a cross-sectional study, found lower absenteeism associated with humidification in schools, and even lower absenteeism associated with humidification in both schools and homes. These findings were internally consistent, despite substantial limitations in design of the study, which included only one humidified school and scant statistical analysis.

\section{Characteristics of Buildings and Performance or Attendance}

Berner (1993), from a cross-sectional study of schools, reported that poorer physical condition of school facilities, based on standardized facility inspection checklists, was associated with impaired performance on achievement tests. Average achievement scores increased 5.4 points 
$(p<0.05)$ for each improved category of building condition (i.e., "poor" to "fair" to "excellent"). The design of this study had important limitations, such as limited control for major confounders like socioeconomic status that would be expected to exaggerate the associations found. However, the analysis was carefully done, and some reported analyses adjusting for level of parental economic input at the school (PTA budget per student) estimated an even stronger association (increased scores of 10.8 with each improvement of building condition category, $\mathrm{p}<$ 0.005). These findings, of positive relations between visible conditions of school facilities and objective measures of student performance, are suggestive, but it is not clear what causal agents the visible condition of school facilities represents, as the study did not consider IEQ or health effects.

Nilsen et al. (2002) reported findings from a year-long, controlled, blinded, 2-group, before-after quasi-experimental study of improved office cleaning, on two floors in a single building, with about 50 workers per group. The intervention led to a nonsignificant improvement in mental states potentially related to performance, but no improvement in performance assessed by tests. Sickness absence significantly improved (by $16.4 \%$ relative to the control group, with no data provided on precision), mostly from reduced short-term sick leave. Despite its generally strong design, this study in only two groups without crossover provides, by itself, suggestive (but not strongly suggestive) evidence for a relationship between increased office cleaning and reduced sickness absence.

\section{Outdoor pollutants and performance or attendance}

A substantial literature of strongly designed cohort studies is available on associations between outdoor pollutants and attendance of children at school. Because many outdoor pollutants enter readily into the air indoors, and people spend the great majority of their time indoors (although children less than adults), it is likely that these study findings largely reflect effects from indoor exposures. For instance, ranges of measured indoor/outdoor concentration ratios of outdoor pollutants at schools with negligible indoor sources have been reported for ozone (0.3-0.8) (Weschler, 2000); carbon monoxide (0.6-0.9) (Chaloulakou and Mavroidis, 2002; Chaloulakou et al., 2003); and oxides of nitrogen (Blondeau et al., 2004). Clearly a substantial proportion of childrens' total exposure to these outdoor pollutants could occur inside schools.

The following studies of effects from outdoor pollutants were all considered to be of strong design. Four studies suggested that absence from school increased with higher outdoor concentrations of ozone (Romieu et al., 1992; Chen et al., 2000; Gilliland et al., 2001; Park et al., 2002a). The one available study on sulfur dioxide reported that higher concentrations were associated with a significant increase in illness absence (Park et al., 2002a). Findings were mixed on associations of school absence with outdoor nitrogen oxides (Hwang et al., 2000; Gilliland et al., 2001; Park et al., 2002a), carbon monoxide (Chen et al., 2000; Park et al., 2002a), and concentrations of particles less than 10 micrometers in aerodynamic diameter (PM10) (Ransom and Pope, 1992; Chen et al., 2000; Gilliland et al., 2001).

IEQ, health, and performance or attendance

Although limited research, particularly on children in schools, is available directly associating IEQ factors with performance or attendance, an extensive scientific literature exists on other relationships that form plausible links in causal chains connecting IEQ to performance or 
attendance (Figure 2). This section briefly summarizes available evidence from primary studies or review articles on a number of relationships that may indirectly link pollutant and thermal aspects of IEQ to performance or attendance: between IEQ and health, between health and attendance or performance, and between attendance and performance.

Indoor pollutants or thermal conditions and health

This section first lists recent publications that have extensively reviewed aspects of relationships between IEQ and health outcomes. The section next cites articles reporting primary research on health and a broad range of IEQ factors, including measured pollutants or thermal conditions and HVAC or building characteristics. Here again, as in the review of direct associations with performance and attendance, because limited research was available specifically on children, these summaries include findings on children or adults in any indoor setting. We believe it is likely that findings of health effects from indoor environments on adults may be useful in predicting health effects of school environments on children; however, lack of findings in adults do not imply lack of effects in children, who may be more sensitive.

The articles are grouped by types of health effect, and the health effects are roughly categorized by how strongly current evidence has associated them with effects on performance and absenteeism (see section below on "Health and performance or attendance"). Only articles on health effects demonstrated or considered likely to have performance effects are included here and in Table 3; articles on other health effects are included in Appendix 2 (available at the journal's web-site. Articles reporting findings on children (in either schools, day-care centers, or homes) are presented in bold type.

Review articles or chapters (none focusing specifically on children in schools) are available on the following topics: indoor environments and respiratory infections (Fisk, 2000); indoor environments and asthma, including a section on schools (Committee on the Assessment of Asthma and Indoor Air, 2000); dampness in buildings and health (Bornehag et al., 2001); ventilation rates and health in buildings (Seppanen et al., 1999); HVAC system type and symptoms in buildings (Seppanen and Fisk, 2002); and various aspects of relationships between IEQ and health (Spengler et al., 2000).

Respiratory infections and asthma, among the health effects potentially associated with buildings, have the most available evidence associating them directly with occupant performance. There are two likely mechanisms by which IEQ-related risk factors for asthma and respiratory disease could impair the performance of building occupants. First, respiratory infections and asthma are associated with increased absenteeism (Dixon, 1985; Fowler et al., 1992; Weiss and Sullivan, 1994; Smith et al., 1997), and this absenteeism seems likely, based on available evidence, to decrease performance among both students and workers (see section below on "Attendance and performance"). In addition, these health outcomes seem likely, based on available evidence, to directly impair performance; e.g., Smith (1990).

Table 3 lists, with relevant citations, risk factors identified in buildings for respiratory infections and for asthma or potentially related effects, such as increased pulmonary function variability, pulmonary hyper-responsiveness, or decreased pulmonary function. Table 3 also lists risk factors for other IEQ-associated health effects with potential effects on performance - atopy, 
asthmatic symptoms, bronchial obstruction, allergic alveolitis, and neurologic symptoms. Appendix 2 lists risks for other IEQ-related health effects with uncertain connections with performance - lung inflammation, nasal swelling/congestion/inflammation, increased moldspecific immunoglobulins, irritant symptoms, and unspecified symptoms.

Health and performance or attendance Absenteeism from viral respiratory infections is well recognized (Dixon, 1985; Fisk, 2000). Research has clearly documented that school absenteeism is more frequent among asthmatic children, or those with respiratory symptoms, than well children, and that absenteeism increases with severity of the disease (Parcel et al., 1979; Fowler et al., 1992; Bussing et al., 1995; McCowan et al., 1996; Spee-van der Wekke et al., 1998; Diette et al., 2000; Silverstein et al., 2001). Available studies have consistently shown a relationship between allergies and increased absenteeism, in schools (McLoughlin et al., 1983) and in offices (Preller et al., 1990; CrystalPeters et al., 2000).

Asthma has been associated, in many studies (Fowler et al., 1992; Bussing et al., 1995; Austin et al., 1998; Rietveld and Colland, 1999; Diette et al., 2000) but not all (Gutstadt et al., 1989; Lindgren et al., 1992; Silverstein et al., 2001), with reduced performance among schoolchildren. Multiple studies have demonstrated that allergies are associated with reduced performance among adults (Crystal-Peters et al., 2000; Burton et al., 2001; Wilken et al., 2002) but not among children (McLoughlin et al., 1983). Various symptoms experienced in buildings have been associated with reduced performance among both school children (Landrus and Axcel, 1990; Diette et al., 2000) and office workers (Raw et al., 1990; Hall et al., 1991; Nunes et al., 1993). Viral respiratory infections, according to a strong experimental study by Smith (1990), adversely affect some aspects of adult performance.

Attendance and performance

Of 11 studies reviewed here, seven found increased school absences to be correlated with a measure of school performance (Douglas and Ross, 1965; Ziomeck and Schoenberger, 1983; Safer, 1986; Ehrenberg et al., 1991; Marburger, 2001; Rodgers, 2001; Silverstein et al., 2001), three did not (Port, 1979; O'Brien et al., 1985; Gutstadt et al., 1989), and one had mixed findings (O'Neil et al., 1985). The overall picture from the 11 studies is of a clear correlation between school absenteeism and performance. While much of this correlation may result from mutually associated confounding factors such as motivation or personal factors, some of the association, best demonstrated by the two most strongly designed studies (Rodgers (2001) and Marburger (2001)), is likely to be causal. While the strongest studies found a direct relationship between increased absence and decreased short-term learning in college courses, it is not clear how multiple reductions in short-term learning from specific absences might aggregate into reduced long-term learning. It is also not clear to what extent these effects demonstrated best in college classes also occur in primary and secondary school. 
Table 3. IEQ-related risk factors for health effects with documented or likely adverse impacts on performance or attendance of occupants* (findings related to children are presented in bold typeface)

\begin{tabular}{|c|c|c|c|}
\hline Performance Risk & Health Outcome & IEQ-Related Risk Factor & Reference \\
\hline & $\begin{array}{l}\text { Respiratory infections - } \\
\text { colds, sore throat, } \\
\text { influenza, pulmonary } \\
\text { infections, TB }\end{array}$ & $\begin{array}{l}\text { Nitrogen dioxide } \\
\text { Low ventilation rate } \\
\text { Renovation/styrene/benzene } \\
\text { Moisture damage } \\
\text { Molds } \\
\text { Lack of humidification } \\
\text { Humidification } \\
\text { Painting during pregnancy } \\
\text { New flooring during pregnancy } \\
\text { Styrene, benzene }\end{array}$ & $\begin{array}{l}\text { (Pilotto et al., 1997) } \\
\text { (Fisk, 2000; Menzies et al., 2000; Milton et al., 2000) } \\
\text { (Diez et al., 2000) } \\
\text { (Husman et al., 2002) } \\
\text { (Jacob et al., 2002; Muller et al., 2002; Norback et al., } \\
\text { 2002) } \\
\text { (Green, 1985) } \\
\text { (Milton et al., 2000) } \\
\text { (Diez et al., 2000) } \\
\text { (Diez et al., 2000) } \\
\text { (Diez et al., 2000) }\end{array}$ \\
\hline $\begin{array}{l}\text { Documented } \\
\text { Attendance Effects, } \\
\text { Likely Performance } \\
\text { Effects }\end{array}$ & $\begin{array}{l}\text { Asthma, bronchial } \\
\text { hyperresponsiveness, } \\
\text { increased pulmonary } \\
\text { function variability, } \\
\text { decreased pulmonary } \\
\text { function }\end{array}$ & $\begin{array}{l}\text { Fungi in air or dust } \\
\text { Total bacteria in air } \\
\text { Endotoxin } \\
\text { Dust mites } \\
\text { Animal dander } \\
\text { Formaldehyde } \\
\text { Chemicals in cleaning compounds } \\
\text { Pollutants, outdoor } \\
\text { Dampness/water damage } \\
\text { Carpets } \\
\text { Open shelves }\end{array}$ & $\begin{array}{l}\text { (Smedje et al., 1997);(Hoffman et al., 1993; Garrett et al., } \\
\text { 1998a; Garrett et al., 1998b; Seuri et al., 2000b; Sigsgaard et } \\
\text { al., 2002) } \\
\text { (Smedje et al., 1997) } \\
\text { (Michel et al., 1996; Michel et al., 2001) } \\
\text { (Platts-Mills, 2000) } \\
\text { (Smedje et al., 1997); (Platts-Mills, 2000) } \\
\text { (Smedje et al., 1997; Rumchev et al., 2002) } \\
\text { (McCoach et al., 1999; Zock et al., 2001) } \\
\text { (Guo et al., 1999; Steerenberg et al., 2001) } \\
\text { (Taskinen et al., 1997; Taskinen et al., 2000; Jarvis and } \\
\text { Morey, 2001) } \\
\text { (Hansen et al., 1987) } \\
\text { (Smedje et al., 1997) }\end{array}$ \\
\hline $\begin{array}{l}\text { Likely Performance } \\
\text { Effects }\end{array}$ & Atopy & $\begin{array}{l}\text { Fungi in air or dust } \\
\text { Formaldehyde } \\
\text { Dampness/water damage/mold } \\
\text { Vehicle exhaust }\end{array}$ & $\begin{array}{l}\text { (Garrett et al., 1998b; Muller et al., 2002) } \\
\text { (Garrett et al., 1999) } \\
\text { (Taskinen et al., 2000; Savilahti et al., 2001) } \\
\text { (Wyler et al., 2000) }\end{array}$ \\
\hline
\end{tabular}




\begin{tabular}{|c|c|c|c|}
\hline Performance Risk & Health Outcome & IEQ-Related Risk Factor & Reference \\
\hline & $\begin{array}{l}\text { Bronchial obstruction, } \\
\text { asthmatic/lower respiratory } \\
\text { symptoms }\end{array}$ & $\begin{array}{l}\text { PVC flooring } \\
\text { Textile wall materials } \\
\text { Plasticizer-emitting materials } \\
\text { Pollutants, outdoor } \\
\text { Moisture/dirt in HVAC } \\
\text { Moisture damage/dampness/mold } \\
\text { Plastic wall materials } \\
\text { Renovation (painting or flooring) }\end{array}$ & $\begin{array}{l}\text { (Jaakkola et al., 1999) } \\
\text { (Jaakkola et al., 1999) } \\
\text { (Oie et al., 1999) } \\
\text { (Ramadour et al., 2000) } \\
\text { (Mendell et al., 2003) } \\
\text { (Spengler et al., 1994; Oie et al., 1999; Jarvis and Morey, } \\
\text { 2001; Bornehag et al., 2002; Park et al., 2002b) } \\
\text { (Jaakkola et al., 2000) } \\
\text { (Diez et al., 2000) }\end{array}$ \\
\hline & $\begin{array}{l}\text { Allergic alveolitis/ } \\
\text { Hypersensitivity } \\
\text { pneumonitis }\end{array}$ & Dampness/water damage/mold & $\begin{array}{l}\text { (Hodgson et al., 1987; Woodard et al., 1988; Kreiss, 1989; } \\
\text { Thom et al., 1990; Seuri et al., 2000a; Jarvis and Morey, } \\
\text { 2001; Kim et al., 2002) }\end{array}$ \\
\hline & $\begin{array}{l}\text { Neurologic symptoms - } \\
\text { headache, confusion, } \\
\text { difficulty thinking, } \\
\text { difficulty concentrating, } \\
\text { fatigue }\end{array}$ & $\begin{array}{l}\text { Dust, floor } \\
\text { VOCs } \\
\text { Old carpet } \\
\text { Small airborne particles } \\
\text { Higher temperature }\end{array}$ & $\begin{array}{l}\text { (Mølhave et al., 2000) } \\
\text { (Mølhave et al., 1985; Otto et al., 1992) } \\
\text { (Wargocki et al., 1999; Lagercrantz et al., 2000) } \\
\text { (Mendell et al., 2002b) } \\
\text { (Mendell et al., 2002b; Witterseh et al., 2002) }\end{array}$ \\
\hline
\end{tabular}

* findings related to other health effects are presented in an Appendix on the journal's website 


\section{Discussion}

Synthesis of findings

We did not identify a set of findings sufficiently persuasive to establish specific causal relationships between indoor pollutants or thermal conditions in schools and the performance of students. Very little directly relevant research is available. Only seven studies (of which only two were considered to have strong designs) assessed relations between these environmental factors in schools and the performance or attendance of students. We did identify several strongly suggestive or suggestive lines of evidence linking IEQ factors to the performance or attendance of building occupants through connections involving pollutant exposures. Strongly suggestive evidence links higher concentrations of indoor nitrogen dioxide to decreased school attendance by children. Suggestive (although not fully consistent) evidence links low outdoor air ventilation rates in buildings to decreased performance in children and adults, and suggestive but inconsistent evidence links lower ventilation rates with decreased attendance in adults. Suggestive evidence from one fairly strong study links increased cleaning in offices to reduced illness absence in adults, but not to increased performance, and suggestive evidence from another study links presence of relatively new computers with reduced performance of office work. The relationships involving carpets, cleaning, and ventilation, to the extent that they can be generalized to other offices, seem likely to apply to schools as well, assuming that the variety of relevant pollutant exposures is similar, and that children are at least as sensitive to them as adults.

We also found evidence supporting many individual links in a causal chain relating indoor environmental factors to occupant performance and attendance (Figure 2). A large body of evidence, much of it from studies of children, links microbiological and chemical exposures from indoor sources, building characteristics such as excessive dampness, and (possibly indoor) exposures to pollutants from outdoors to respiratory infections, asthma, lower respiratory symptoms, and allergies, all documented to reduce school attendance. Allergic rhinitis has direct associations documented with reduced performance and attendance. Indoor microbiological and chemical pollutants (including emissions from plastics) from indoor sources, and possibly some from outdoor sources, as well as a variety of HVAC and building characteristics, have been related to a broad range of additional health outcomes - allergic alveolitis, atopy, lung inflammation, bronchial obstruction, nasal swelling and inflammation, and a variety of respiratory, irritant, neurologic, and other symptoms - for which links to decreased performance or attendance are possible but have received little assessment. Sufficient information is not available on how directly findings of relationships between indoor non-school environments and health effects in children or adults would apply to children in schools, but it seems reasonable to assume that schools share many of these exposures and that children are at least as sensitive to them as adults.

Fairly consistent correlations between reduced attendance and the performance of college students seem, from findings in the strongest studies, to be at least partly causal. This makes a causal role of increased absence in reducing the performance of students seem likely. Decrements in teacher attendance or performance caused by poor IEQ may be an additional (although still undocumented) indirect cause of decreased performance among students.

Overall, the available evidence suggests that effects of IEQ on performance or attendance of occupants are likely to be mediated through biologic, chemical, or particulate pollutant exposures or through thermal conditions. Characteristics of HVAC systems, buildings, and occupied 
spaces, in ways not fully understood, influence IEQ exposures and conditions, which consequently may adversely affect the health, performance, and attendance of building occupants.

\section{Limitations of review}

This review has been most thorough in identifying and evaluating studies directly relating IEQ to the performance or attendance of building occupants. Identification of studies on other intermediate links was less thorough, and these reports, while subject to basic criteria for inclusion, did not receive methodological evaluation or critique. The review did not include possible important effects of noise, light, or odor, nor did it include the relations of IEQ to discomfort or distraction, and consequent effects on performance.

Since negative studies performed are less likely to be submitted or accepted for publication, they are less likely to be identified in literature reviews such as this, leading to a bias in reviews toward positive findings (Sterne and Egger, 2001). The limited numbers of positive findings identified on any specific topic in this review prevents the use of available graphical checks for this bias. Therefore, the conclusions reported here may be skewed by publication bias toward the positive.

Key data gaps, research questions, and suggested research strategies

This review has identified several pathways through which school environments might reduce the performance and attendance of schoolchildren. Considered together, available high-quality research findings support links along several of these pathways. Critical limitations in the available techniques for measuring the risk factors, exposures, performance outcomes, and intermediate outcomes such as health effects have prevented the further identification and quantification of environmental risks in schools associated with performance or attendance.

For many of the IEQ/performance links reviewed here, however, sufficient evidence is not available even to document consistent statistical associations, much less causality. More evidence is available of statistical associations between aspects of IEQ in buildings (for instance, related to moisture and ventilation rates) and the health of occupants, even if this evidence still fails to establish causal relationships. Thus, more justification exists now for improving IEQ in schools to reduce health risks to students than to reduce performance or attendance risks. However, since IEQ-performance or IEQ-absenteeism links ultimately identified are likely to operate largely through IEQ-health links, IEQ improvements that benefit the health of students may have performance and attendance benefits as well.

Little representative information characterizing the IEQ in U.S. schools is available to guide priority research or remedial actions. An exception is outdoor air ventilation rates, one of the best-documented risk factors for adverse effects on symptoms, if not on performance, in buildings. A broad range of studies, although not representative, suggests that ventilation rates are substantially below recommended levels in many US and European schools (Myhrvold et al., 1996; Bartlett et al., 1999; Braganza et al., 2000; Norback et al., 2000; Smedje and Norback, 2000; Corsi et al., 2002; Daisey et al., 2003). Available studies have consistently associated inadequate ventilation rates in offices to increases in respiratory, irritant, and neurologic symptoms in adult workers. If the indoor exposures in school buildings that are controlled by ventilation are similar to the exposures in office buildings, and if children are at least as sensitive to these indoor exposures as adults, then inadequate school ventilation is now related to a 
substantial excess of preventable symptoms among U.S. school children, with other potential effects on health or performance.

About other aspects of IEQ in U.S. schools, little is known except that the state of repair and general physical conditions in schools are often poor (U.S. General Accounting Office, 1995). With respect to outdoor pollutants entering the indoor air of schools, a recent study has shown that a substantial number of California students, including a disproportionate number of nonwhite and economically disadvantaged students, attend schools near major roads with very high traffic counts, and thus have elevated adjacent outdoor pollutant levels (Green et al., 2004).

The U.S. is in the midst of a multi-billion dollar school construction program (Duke, 1998) to provide classrooms for an expanding school-age population and replace deteriorating existing stock. Unless design and construction of the new schools reflects the critical importance of IEQ, such as by providing adequate ventilation and preventing moisture incursions, this massive program may extend potential ill effects to new generations of children. Research is critical to guide the construction of new schools in ways that support the health and performance of the occupants.

A set of priority research recommendations for improving IEQ to benefit the health of workers in indoor environments, but readily applicable to students in schools, has recently been published (Mendell et al., 2002a). We recommend the following urgent research priorities for improving IEQ to benefit students:

- Investigate the prevalence in schools of exposures or conditions considered likely to have adverse effects on performance, attendance, or health (e.g., low ventilation rates; visible moisture or mold; and high concentrations of formaldehyde, nitrogen dioxide, or outdoor pollutants). Identify sites requiring immediate remediation.

- Establish the consequences of these exposures or conditions for performance, attendance, or health using well-designed studies. Focus initially on exposures or conditions likely to be widespread, effects likely to be relatively common or serious, and situations relatively amenable to remedial or preventive actions.

- Identify effective strategies to prevent or mitigate these exposures or conditions, even before specific causal exposures or mechanisms are fully understood, in order to accelerate public benefits.

The number of non-persuasive studies reviewed here highlights the need for high standards for future research in this area. The strongest studies reviewed here demonstrate that strong study designs, including the best available measurements of exposures and human outcomes, are both feasible and necessary for good IEQ research. Furthermore, multidisciplinary collaboration, including health sciences, social sciences, physical sciences, engineering, and statistics, will greatly enhance the strength of research in this complex area.

\section{Conclusions}

The primary goal of this review was to summarize available knowledge relevant to the effects of indoor school environments and the performance and attendance of children. Little direct scientific evidence of high quality was available. Nevertheless, the findings summarized here 
provide suggestive (and some strongly suggestive) evidence that certain conditions commonly found in U.S. schools have adverse effects on the health and the academic performance of many of the more than 50 million U.S. schoolchildren. Effective public health actions do not always require or wait for documented causality. Thus, these research findings make a strong case for immediate, targeted actions of prevention and mitigation in school environments. These actions include ensuring, throughout the life of each existing and future school building, adequate outdoor ventilation, control of moisture, and avoidance of indoor exposures to microbiologic and chemical substances considered likely to have adverse effects. To guide and improve these actions, additional environmental health research in schools is critical to better identify adverse exposures, quantify their effects, and document effective preventive strategies.

\section{Acknowledgements}

This review was performed, with financial support from the Indoor Environments Division of the U.S. Environmental Protection Agency, for the Indoor Health and Productivity Project of the Subcommittee on Construction and Building, Committee on Technology, National Science and Technology Council. We thank the internal reviewers at Lawrence Berkeley National Laboratory and David Mudarri, Jennifer Veitch, Kay Kreiss, Pawel Wargocki, and Jed Waldman for comments on initial drafts.

\section{References}

Austin, J. K., Huberty, T. J., Huster, G. A., and Dunn, D. W., (1998) Academic achievement in children with epilepsy or asthma. Dev Med Child Neurol, 40: 248-255.

Bakó-Biró, Z., Wargocki, P., Weschler, C. J., and Fanger, P. O., (2004) Effects of pollution from personal computers on perceived air quality, SBS symptoms and productivity in offices. Indoor Air, 14: 178-187.

Bartlett, K. H., Kennedy, S. M., Brauer, M., Dill, B., and van Netten, C., (1999) Predictors of exposure to indoor $\mathrm{CO} 2$ and bioaerosols in elementary school classrooms. Indoor Air '99: Proceedings of the 8th International Conference on Indoor Air Quality and Climate, 1: 252-257.

Bayer, C. W., Crow, S. A., and J., F., (2000) Causes of indoor air quality problems in schools: Summary of scientific research. SEMCO, Inc., Columbia, MO.

Berner, M., (1993) Building conditions, parental involvement, and student achievement in the District of Columbia public school system. Urban Education, 28: 6-29.

Blondeau, P., Iordache, V., Poupard, O., Genin, D., and Allard, F., (2004) Relationship between outdoor and indoor air quality in eight French schools. Indoor Air.

Bornehag, C. G., Blomquist, G., Gyntelberg, F., Jarholm, B., Malmberg, P., Nordvall, L., Nielsen, A., Pershagen, G., and Sundell, J., (2001) Dampness in buildings and health: Nordic interdisciplinary review of the scientific evidence on associations between exposure to "dampness" in buildings and health effects (NORDDAMP). Indoor Air, 11: $72-86$.

Bornehag, C. G., Sundell, J., Hagerhed, L., Janson, S., and DBH-study group, (2002) Dampness in buildings and health. Dampness at home as a risk factor for symptoms among 10851 swedish children (DBH-step 1). Indoor Air '02: Proceedings of the 9th International Conference on Indoor Air Quality and Climate. 
Braganza, E., Fontana, C., and Harrison, J., (2000) Baseline measurements of indoor air quality comfort parameters in eight United States elementary and secondary schools. Proceedings of Healthy Buildings 2000, 1: 193-198.

Burton, W. N., Conti, D. J., Chen, C. Y., Schultz, A. B., and Edington, D. W., (2001) The impact of allergies and allergy treatment on worker productivity. J Occup Environ Med, 43: 6471.

Bussing, R., Halfon, N., Benjamin, B., and Wells, K. B., (1995) Prevalence of behavior problems in US children with asthma. Arch Pediatr Adolesc Med, 149: 565-572.

Chaloulakou, A. and Mavroidis, I., (2002) Comparison of indoor and outdoor concentrations of $\mathrm{CO}$ at a public school. Evaluation of an indoor air quality model. Atmos Environ, 36: 1169-1181.

Chaloulakou, A., Mavroidis, I., and Duci, A., (2003) Indoor and outdoor carbon monoxide concentration relationships at different microenvironments in the Athens area. Chemosphere, 52: 1007-1019.

Chen, L., Jennison, B. L., Yang, W., and Omaye, S. T., (2000) Elementary school absenteeism and air pollution. Inhal Toxicol, 12: 997-1016.

Committee on the Assessment of Asthma and Indoor Air, (2000) Clearing the Air: Asthma and Indoor Exposures. Washington, D.C.: National Academy Press.

Cook, T. D. and Campbell, D. T., (1979) Quasi Experimentation: Design \& Analysis for Field Settings. Chicago: Rand McNally College Publishing Company.

Corsi, R. L., Torres, V. M., Sanders, M., and Kinney, K. L., (2002) Carbon Dioxide Levels and Dynamics in Elementary Schools: Results of the TESIAS Study. Indoor Air '02: Proceedings of the 9th International Conference on Indoor Air Quality and Climate.

Crystal-Peters, J., Crown, W. H., Goetzel, R. Z., and Schutt, D. C., (2000) The cost of productivity losses associated with allergic rhinitis. Am J Managed Care, 6: 373-378.

Daisey, J. M. and Angell, W. J., (1998) A Survey and Critical Review of the Literature on Indoor Air Quality, Ventilation and Health Symptoms in Schools. Lawrence Berkeley National Laboratory, Berkeley, CA.

Daisey, J. M., Angell, W. J., and Apte, M. G., (2003) Indoor Air Quality, ventilation and health symptoms in schools: an analysis of existing information. Indoor Air, 13: 53-64.

Diette, G. B., Markson, L., Skinner, E. A., Nguyen, T. T., Algatt-Bergstrom, P., and Wu, A. W., (2000) Nocturnal asthma in children affects school attendance, school performance, and parents' work attendance. Arch Pediatr Adolesc Med, 154: 923-928.

Diez, U., Kroessner, T., Rehwagen, M., Richter, M., Wetzig, H., Schulz, R., Borte, M., Metzner, G., Krumbiegel, P., and Herbarth, O., (2000) Effects of indoor painting and smoking on airway symptoms in atopy risk children in the first year of life: results of the LARSstudy. Leipzig Allergy High-Risk Children Study. Int J Hyg Environ Health, 203: 23-28.

Dixon, R. E., (1985) Economic costs of respiratory tract infections in the United States. Am J Med, 78: 45-51.

Douglas, J. W. B. and Ross, J. M., (1965) The effects of absence on primary school performance. British J Educ Psych, XXXV: 28-40.

Duke, P. L., (1998) Does it matter where our children learn? University of Virginia, Washington.

Ehrenberg, R. G., Ehrenberg, R. A., Rees, D. I., and Ehrenberg, E. L., (1991) School-District Leave Policies, Teacher Absenteeism, and Student-Achievement. J Human Resources, 26: 72-105.

Fang, L., Wyon, D. P., Clausen, G., and Fanger, P. O., (2002) Sick building syndrome symptoms and performance in a field laboratatory study at different levels of temperature and 
humidity. Indoor Air '02: Proceedings of the 9th International Conference on Indoor Air Quality and Climate, 3: 466-461.

Faustman, E. M., Silbernagel, S. M., Fenske, R. A., Burbacher, T. M., and Ponce, R. A., (2000) Mechanisms underlying children's susceptibility to environmental toxicants. Environ Health Perspec, 108 Suppl. 1: 13-21.

Federspiel, C. C., Liu, G., Lahiff, M., Faulkner, D., Dibartolomeo, D. L., Fisk, W. J., Price, P. N., and Sullivan, D. P., (2002) Worker performance and ventilation: analyses of individual data for call-center workers. Indoor Air '02: Proceedings of the 9th International Conference on Indoor Air Quality and Climate, 1: 796-801.

Fisk, W. J., (2000) Estimates of potential nationwide productivity and health benefits from better indoor environments: an update. In Spengler, J., Samet, J. M., and McCarthy, J. F. (eds.), Indoor Air Quality Handbook. New York: McGraw-Hill, 4.1-4.36.

Fowler, M. G., Davenport, M. G., and Garg, R., (1992) School functioning of US children with asthma. Pediatrics, 90: 939-944.

Garrett, M. H., Abramson, M. J., Hooper, B. M., Rayment, P. R., Strasser, R. P., and Hooper, M. A., (1998a) Indoor environmental risk factors for respiratory health in children. Indoor Air, 8: 236-243.

Garrett, M. H., Rayment, P. R., Hooper, M. A., Abramson, M. J., and Hooper, B. M., (1998b) Indoor airborne fungal spores, house dampness and associations with environmental factors and respiratory health in children. Clin Exp Allergy, 28: 459-467.

Garrett, M. H., Hooper, M. A., Hooper, B. M., Rayment, P. R., and Abramson, M. J., (1999) Increased risk of allergy in children due to formaldehyde exposure in homes. Allergy, 54: 330-337.

Gilliland, F. D., Berhane, K., Rappaport, E. B., Thomas, D. C., Avol, E., Gauderman, W. J., London, S. J., Margolis, H. G., McConnell, R., Islam, K. T., and Peters, J. M., (2001) The effects of ambient air pollution on school absenteeism due to respiratory illnesses. Epidemiology, 12: 43-54.

Green, G. H., (1974) The effect of indoor relative humidity on absenteeism and colds in schools. ASHRAE Trans, 80: 131-141.

Green, G. H., (1985) Indoor relative humidities in winter and the related absenteeism. Ashrae Transactions, 91: 643-653.

Green, R. S., Smorodinsky, S., Kim, J. J., McLaughlin, R., and Ostro, B., (2004) Proximity of California Public Schools to Busy Roads. Environ Health Perspect, 112: 61-66.

Guo, Y. L., Lin, Y. C., Sung, F. C., Huang, S. L., Ko, Y. C., Lai, J. S., Su, H. J., Shaw, C. K., Lin, R. S., and Dockery, D. W., (1999) Climate, traffic-related air pollutants, and asthma prevalence in middle-school children in taiwan. Environ Health Perspect, 107: 10011006.

Gutstadt, L. B., Gillette, J. W., Mrazek, D. A., Fukuhara, J. T., LaBrecque, J. F., and Strunk, R. C., (1989) Determinants of school performance in children with chronic asthma. Am J Dis Child, 143: 471-475.

Hall, H. I., Leaderer, B. P., Cain, W. S., and Fidler, A. T., (1991) Influence of building-related symptoms on self-reported productivity. Proceedings of IAQ '91: Healthy Buildings, 1: 33-35.

Hansen, L., Bach, E., Ibsen, K., and Osterballe, K., (1987) Carpeting in schools as an indoor pollutant. Indoor Air '87: Proceedings of the 4th International Conference on Indoor Air Quality and Climate, 2: 727-731.

Hodgson, M. J., Morey, P. R., Simon, J. S., Waters, T. D., and Fink, J. N., (1987) An outbreak of recurrent acute and chronic hypersensitivity pneumonitis in office workers. Am J Epidemiol, 125: 631-638. 
Hoffman, R. E., Wood, R. C., and Kreiss, K., (1993) Building-related asthma in Denver office workers. Am J Public Health, 83: 89-93.

Husman, T., Meklin, T., Vepsalainen, A., Vahteristo, M., Koivisto, J., Halla-aho, J., Hyvarinen, A., Koponen, V., and Nevalainen, A., (2002) Respiratory infections among children in moisture damaged schools. Indoor Air '02: Proceedings of the 9th International Conference on Indoor Air Quality and Climate.

Hwang, J. S., Chen, Y. J., Wang, J. D., Lai, Y. M., Yang, C. Y., and Chan, C. C., (2000) Subjectdomain approach to the study of air pollution effects on schoolchildren's illness absence. Am J Epidemiol, 152: 67-74.

Jaakkola, J. J., Oie, L., Nafstad, P., Botten, G., Samuelsen, S. O., and Magnus, P., (1999) Interior surface materials in the home and the development of bronchial obstruction in young children in Oslo, Norway. Am J Public Health, 89: 188-192.

Jaakkola, J. J., Verkasalo, P. K., and Jaakkola, N., (2000) Plastic wall materials in the home and respiratory health in young children. Am J Public Health, 90: 797-799.

Jacob, B., Ritz, B., Gehring, U., Koch, A., Bischof, W., Wichmann, H. E., and Heinrich, J., (2002) Indoor exposure to molds and allergic sensitization. Environ Health Perspect, 110: $647-653$.

Jarvis, J. Q. and Morey, P. R., (2001) Allergic respiratory disease and fungal remediation in a building in a subtropical climate. Appl Occup Environ Hyg, 16: 380-388.

Kim, C. S., Lim, Y. W., Yang, J. Y., Hong, C. S., and Shin, D. C., (2002) Effect of Indoor CO2 concentrations on Wheezing Attacks in Children. Indoor Air '02: Proceedings of the 9th International Conference on Indoor Air Quality and Climate.

Kreiss, K., (1989) The epidemiology of building-related complaints and illness. Occup Med, 4: 575-592.

Lagercrantz, L., Wistrand, M., Willen, U., Wargocki, P., Witterseh, T., and Sundell, J., (2000) Negative impact of air pollution on productivity: Previous Danish findings repeated in new Swedish test room. Proceedings of Healthy Buildings 2000, 1: 653-658.

Landrigan, P. J., (1998) Environmental hazards for children in USA. Int J Occup Med Environ Health, 11: 189-194.

Landrus, G. and Axcel, T., (1990) Survey of asthma, allergy, and environmental sensitivity in an urban Canadian school system. Indoor Air '90: Proceedings of the 5th International Conference on Indoor Air Quality and Climate, 1: 49-52.

Levin, H., (1995) Physical factors in the indoor environment. Occup Med, 10: 59-94.

Lindgren, S., Lokshin, B., Stromquist, A., Weinberger, M., Nassif, E., McCubbin, M., and Frasher, R., (1992) Does asthma or treatment with theophylline limit children's academic performance? N Engl J Med, 327: 926-930.

Marburger, D. R., (2001) Absenteeism and undergraduate exam performance. J Econ Educ, 32: 99-109.

McCoach, J. S., Robertson, A. S., and Burge, P. S., (1999) Floor cleaning materials as a cause of occupational asthma. Indoor Air '99: Proceedings of the 8th International Conference on Indoor Air Quality and Climate, 5: 459-463.

McCowan, C., Bryce, F. P., Neville, R. G., Crombie, I. K., and Clark, R. A., (1996) School absence--a valid morbidity marker for asthma? Health Bull (Edinb), 54: 307-313.

McLoughlin, J., Nall, M., Isaacs, B., Petrosko, J., Karibo, J., and Lindsey, B., (1983) The relationship of allergies and allergy treatment to school performance and student behavior. Ann Allergy, 51: 506-510.

McNall, P. E. and Nevins, R. G., (1967) Comfort and academic achievement in an airconditioned junior high school - a summary evaluation of the Pinellas County experiment. Ashrae Transactions, 73: 3.1-3.17. 
Mendell, M. J. and Smith, A. H., (1990) Consistent pattern of elevated symptoms in airconditioned office buildings: a reanalysis of epidemiologic studies. Am J Public Health, 80: 1193-1199.

Mendell, M. J., (1993) Non-specific symptoms in office workers: A review and summary of the epidemiologic literature. Indoor Air, 3: 227-236.

Mendell, M. J., Fisk, W. J., Kreiss, K., Levin, H., Alexander, D., Cain, W. S., Girman, J. R., Hines, C. J., Jensen, P. A., Milton, D. K., Rexroat, L. P., and Wallingford, K. M., (2002a) Improving the health of workers in indoor environments: priority research needs for a national occupational research agenda. Am J Public Health, 92: 1430-1440.

Mendell, M. J., Fisk, W. J., Petersen, M. R., Hines, C. J., Dong, M., Faulkner, D., Deddens, J. A., Ruder, A. M., Sullivan, D., and Boeniger, M. F., (2002b) Indoor particles and symptoms among office workers: results from a double-blind cross-over study. Epidemiology, 13: 296-304.

Mendell, M. J., Naco, G. N., Wilcox, T. G., and Sieber, W. K., (2003) Environmental risk factors and work-related lower respiratory symptoms in 80 office buildings: an exploratory analysis of NIOSH data. Am J Ind Med, 43: 630-641.

Menzies, D., Fanning, A., Yuan, L., and FitzGerald, J. M., (2000) Hospital ventilation and risk for tuberculous infection in Canadian health care workers. Canadian Collaborative Group in Nosocomial Transmission of TB. Ann Intern Med, 133: 779-789.

Michel, O., Kips, J., Duchateau, J., Vertongen, F., Robert, L., Collet, H., Pauwels, R., and Sergysels, R., (1996) Severity of asthma is related to endotoxin in house dust. Am J Respir Crit Care Med, 154: 1641-1646.

Michel, O., Dentener, M., Corazza, F., Buurman, W., and Rylander, R., (2001) Healthy subjects express differences in clinical responses to inhaled lipopolysaccharide that are related with inflammation and with atopy. J Allergy Clin Immunol, 107: 797-804.

Milton, D. K., Glencross, P. M., and Walters, M. D., (2000) Risk of sick leave associated with outdoor air supply rate, humidification, and occupant complaints. Indoor Air, 10: 212221.

Mølhave, L., Bach, B., and Federsen, O. F., (1985) Human reactions to low concentrations of volatile organic compounds. Environment International, 12: 167-175.

Mølhave, L., Kjaergaard, S. K., and Attermann, J., (2000) Sensory and other neurogenic effects of exposures to airborne office dust. Proceedings of Healthy Buildings 2000, 1: 501-506.

Muller, A., Lehmann, I., Seiffart, A., Diez, U., Wetzig, H., Borte, M., and Herbarth, O., (2002) Increased incidence of allergic sensitisation and respiratory diseases due to mould exposure: results of the Leipzig Allergy Risk children Study (LARS). Int J Hyg Environ Health, 204: 363-365.

Myatt, T. A., Staudenmayer, J., Adams, K., Walters, M., Wand, M., Rudnick, S., and Milton, D. K., (2002) An intervention study of outdoor air supply rates and sick leave among office workers. Indoor Air '02: Proceedings of the 9th International Conference on Indoor Air Quality and Climate, 1: 778-783.

Myhrvold, A. N., Olsen, E., and Lauridsen, O., (1996) Indoor envrionment in schools - Pupils health and performance in regard to $\mathrm{CO} 2$ concentrations. Indoor Air '96: Proceedings of the 7th International Conference on Indoor Air Quality and Climate, 4: 369-374.

Nilsen, S. K., Blom, P., Rydock, J., Nersveen, J., and Fostervold, K., (2002) An intervention study of the relationships between indoor air-related health problems, productivity and cleanliness in an office setting. Indoor Air '02: Proceedings of the 9th International Conference on Indoor Air Quality and Climate, 3: 472-477. 
Norback, D., Walinder, R., Wieslander, G., Smedje, G., Erwall, C., and Venge, P., (2000) Indoor air pollutants in schools: nasal patency and biomarkers in nasal lavage. Allergy, 55: 163170.

Norback, D., Mi, Y.-H., Larsson, L., Wady, L., Tao, J., and Mi, Y.-L., (2002) Current asthma, respiratory infections and hypersensitivity to moulds in pupils in Shanghai, China, in relation to micorbial components in the classrooms. Indoor Air '02: Proceedings of the 9th International Conference on Indoor Air Quality and Climate.

Nunes, F., Menzies, R., Tamblyn, R. M., Boehm, E., and Letz, R., (1993) The effect of varying level of outdoor air supply on neurobehavioural performance function during a study of sick building syndrome (sbs). Indoor Air '93: Proceedings of the 6th International Conference on Indoor Air Quality and Climate, 1: 53-59.

O'Brien, L. M., Meszaros, B., and Pulliam, W., (1985) Effects of teacher use of objectives on student achievement in social studies. Theory Res Soc Educ, 8: 57-65.

Oie, L., Nafstad, P., Botten, G., Magnus, P., and Jaakkola, J. K., (1999) Ventilation in homes and bronchial obstruction in young children. Epidemiology, 10: 294-299.

O'Neil, S. L., Barysh, N., and Setear, S. J., (1985) Determining school programming needs of special population groups: a study of asthmatic children. J Sch Health, 55: 237-239.

Otto, D. A., Hudnell, H. K., House, D. E., Molhave, L., and Counts, W., (1992) Exposure of humans to a volatile organic mixture. I. Behavioral assessment. Arch Environ Health, 47: 23-30.

Parcel, G. S., Gilman, S. C., Nader, P. R., and Bunce, H., (1979) A comparison of absentee rates of elementary schoolchildren with asthma and nonasthmatic schoolmates. Pediatrics, 64: 878-881.

Park, H., Lee, B., Ha, E. H., Lee, J. T., Kim, H., and Hong, Y. C., (2002a) Association of air pollution with school absenteeism due to illness. Arch Pediatr Adolesc Med, 156: 12351239.

Park, J. H., Schleiff, P. L., Attfield, M. D., Cox-Ganser, J. M., and Kreiss, K., (2002b) Semiquantitative mold exposure index predicts building-related respiratory symptoms. Indoor Air '02: Proceedings of the 9th International Conference on Indoor Air Quality and Climate.

Pepler, R. D. and Warner, R. E., (1968) Temperature and learning: An experimental study. Ashrae Transactions, 74: 211-219.

Pilcher, J. J., Nadler, E., and Busch, C., (2002) Effects of hot and cold temperature exposure on performance: a meta-analytic review. Ergonomics, 45: 682-698.

Pilotto, L. S., Douglas, R. M., Attewell, R. G., and Wilson, S. R., (1997) Respiratory effects associated with indoor nitrogen dioxide exposure in children. Int J Epidemiol, 26: 788796.

Platts-Mills, T. A. E., (2000) Allergens derived from arthropods and domestic animals. In Spengler, J., Samet, J. M., and McCarthy, J. F. (eds.), Indoor Air Quality Handbook. New York: McGraw-Hill, 43.41-43.15.

Port, R. J., (1979) The relationship between the achievement of students on the HSTEC and specific student background and school-related variables. Educ Perspec, 18: 18-22.

Preller, L., Zweers, T., Brunekreef, B., and Boleij, J. S. M., (1990) Sick leave due to workrelated health complaints among office workers in the Netherlands. Indoor Air '90: Proceedings of the 5th International Conference on Indoor Air Quality and Climate, 1: 227-230.

Ramadour, M., Burel, C., Lanteaume, A., Vervloet, D., Charpin, D., Brisse, F., and Dutau, H., (2000) Prevalence of asthma and rhinitis in relation to long-term exposure to gaseous air pollutants. Allergy, 55: 1163-1169. 
Ransom, M. R. and Pope, C. A., 3rd, (1992) Elementary school absences and PM10 pollution in Utah Valley. Environ Res, 58: 204-219.

Raw, G. J., Roys, M. S., and Leaman, A., (1990) Further findings from the office environment survey: productivity. Indoor Air '90: Proceedings of the 5th International Conference on Indoor Air Quality and Climate, 1: 231-236.

Richards, W., (1986) Allergy, asthma, and school problems. J Sch Health, 56: 151-152.

Rietveld, S. and Colland, V. T., (1999) The impact of severe asthma on schoolchildren. $J$ Asthma, 36: 409-417.

Rodgers, J. R., (2001) A panel-data study of the effect of student attendance on university performance. Aust J Educ, 45: 284-295.

Romieu, I., Lugo, M. C., Velasco, S. R., Sanchez, S., Meneses, F., and Hernandez, M., (1992) Air pollution and school absenteeism among children in Mexico City. Am J Epidemiol, 136: 1524-1531.

Rosen, K. G. and Richardson, G., (1999) Would removing indoor air particulates in children's environments reduce rate of absenteeism--a hypothesis. Sci Total Environ, 234: 87-93.

Rothman, K. J., (1986) Modern Epidemiology. Boston: Little, Brown and Company.

Rumchev, K., Spickett, J., Phillips, M., and Stick, S., (2002) Indoor Air Quality in Houses of Asthmatic and Non-Asthmatic Children. Indoor Air '02: Proceedings of the 9th International Conference on Indoor Air Quality and Climate.

Safer, D., (1986) Nonpromotion correlates and outcomes at different grade levels. Journal of Learning Disabilities, 19: 500-503.

Sale, C. S., (1972) Humidification to reduce respiratory illnesses in nursery school children. South Med J, 65: 882-885.

Savilahti, R., Uitti, J., Roto, P., Laippala, P., and Husman, T., (2001) Increased prevalence of atopy among children exposed to mold in a school building. Allergy, 56: 175-179.

Schoer, L. and Shaffran, J., (1973) A combined evaluation of three separate research projects on the effects of thermal environment on learning and performance. ASHRAE Trans, 79: 97108.

Sensharma, N. P., Woods, J. E., and Goodwin, A. K., (1998) Relationships between the indoor environment and productivity: a literature review. ASHRAE Trans: Res, 104, part 1A: 686-701.

Seppanen, O., Fisk, W. J., and Mendell, M. J., (1999) Association of ventilation rates and CO2 concentrations with health and other responses in commercial and institutional buildings. Indoor Air, 9: 226-252.

Seppanen, O. and Fisk, W. J., (2002) Association of ventilation system type with SBS symptoms in office workers. Indoor Air, 12: 98-112.

Seuri, M., Husman, K., Kinnunen, H., Reiman, M., Kreus, R., Kuronen, P., Lehtomaki, K., and Paananen, M., (2000a) An outbreak of respiratory diseases among workers at a waterdamaged building--a case report. Indoor Air, 10: 138-145.

Seuri, M., Lehtomaki, K., and Reiman, M., (2000b) Peak expiratory flow follow-up of workers employed in damp buildings. Proceedings of Healthy Buildings 2000, 1: 579-584.

Sigsgaard, T., Plesner, K., Host, A., Meyer, H. W., Wurtz, H., and DAMIB Group, (2002) Moulds in the dust collector and health. Indoor Air '02: Proceedings of the 9th International Conference on Indoor Air Quality and Climate, 3: 421-424.

Silverstein, M. D., Mair, J. E., Katusic, S. K., Wollan, P. C., O'Connell E, J., and Yunginger, J. W., (2001) School attendance and school performance: a population-based study of children with asthma. J Pediatr, 139: 278-283.

Smedje, G., Norback, D., and Edling, C., (1997) Asthma among secondary schoolchildren in relation to the school environment. Clin Exp Allergy, 27: 1270-1278. 
Smedje, G. and Norback, D., (2000) New ventilation systems at select schools in Sweden-effects on asthma and exposure. Arch Environ Health, 55: 18-25.

Smith, A. P., (1990) Respiratory virus infections and performance. Philos Trans R Soc Lond B Biol Sci, 327: 519-528.

Smith, D. H., Malone, D. C., Lawson, K. A., Okamoto, L. J., Battista, C., and Saunders, W. B., (1997) A national estimate of the economic costs of asthma. Am J Respir Crit Care Med, 156: $787-793$.

Spee-van der Wekke, J., Meulmeester, J. F., Radder, J. J., and Verloove-Vanhorick, S. P., (1998) School absence and treatment in school children with respiratory symptoms in The Netherlands: data from the Child Health Monitoring System. J Epidemiol Community Health, 52: 359-363.

Spengler, J., Neas, L., Nakai, S., Dockery, D., Speizer, F., Ware, J., and Raizenne, M., (1994) Respiratory Symptoms and Housing Characteristics. Indoor Air, 4: 72-82.

Spengler, J. D., Samet, J. M., and McCarthy, J. F., (2000) Indoor Air Quality Handbook. New York: McGraw-Hill.

Steerenberg, P. A., Nierkens, S., Fischer, P. H., van Loveren, H., Opperhuizen, A., Vos, J. G., and van Amsterdam, J. G., (2001) Traffic-related air pollution affects peak expiratory flow, exhaled nitric oxide, and inflammatory nasal markers. Arch Environ Health, 56: 167-174.

Sterne, J. A. and Egger, M., (2001) Funnel plots for detecting bias in meta-analysis: guidelines on choice of axis. J Clin Epidemiol, 54: 1046-1055.

Taskinen, T., Meklin, T., Nousiainen, M., Husman, T., Nevalainen, A., and Korppi, M., (1997) Moisture and mould problems in schools and respiratory manifestations in schoolchildren: clinical and skin test findings. Acta Paediatr, 86: 1181-1187.

Taskinen, T., Laitinen, S., Meklin, T., Husman, T., Nevalainen, A., and Korppi, M., (2000) Skin test and serum IGE reactions to moulds in relation to exposure in children. Proceedings of Healthy Buildings 2000, 1: 233-238.

Thom, D. H., Grayston, J. T., Wang, S. P., Kuo, C. C., and Altman, J., (1990) Chlamydia pneumoniae strain TWAR, Mycoplasma pneumoniae, and viral infections in acute respiratory disease in a university student health clinic population. Am J Epidemiol, 132: 248-256.

U.S. General Accounting Office, (1995) School facilities: condition of America's schools. U.S. GAO, Washington, D.C.

Wargocki, P., Wyon, D. P., Baik, Y. K., Clausen, G., and Fanger, P. O., (1999) Perceived air quality, Sick Building Syndrome (SBS) symptoms and productivity in an office with two different pollution loads. Indoor Air, 9: 165-179.

Wargocki, P., Wyon, D. P., Sundell, J., Clausen, G., and Fanger, P. O., (2000) The effects of outdoor air supply rate in an office on perceived air quality, Sick Building Syndrome (SBS) symptoms and productivity. Indoor Air, 10: 222-236.

Weiss, K. B. and Sullivan, S. D., (1994) Socio-economic burden of asthma, allergy, and other atopic illnesses. Pediatr Allergy Immunol, 5: 7-12.

Weschler, C. J., (2000) Ozone in indoor environments: concentration and chemistry. Indoor Air, 10: $269-288$.

Wilken, J. A., Berkowitz, R., and Kane, R., (2002) Decrements in vigilance and cognitive functioning associated with ragweed-induced allergic rhinitis. Ann Allergy Asthma Immunol, 89: 372-380.

Witterseh, T., Wyon, D. P., and Clausen, G., (2002) The effects of moderate heat stress and open-plan office noise distraction on office work. Indoor Air '02: Proceedings of the 9th International Conference on Indoor Air Quality and Climate, 4: 1084-1089. 
Woodard, E. D., Friedlander, B., Lesher, R. J., Font, W., Kinsey, R., and Hearne, F. T., (1988) Outbreak of hypersensitivity pneumonitis in an industrial setting. Jama, 259: 1965-1969.

Wyler, C., Braun-Fahrlander, C., Kunzli, N., Schindler, C., Ackermann-Liebrich, U., Perruchoud, A. P., Leuenberger, P., and Wuthrich, B., (2000) Exposure to motor vehicle traffic and allergic sensitization. The Swiss Study on Air Pollution and Lung Diseases in Adults (SAPALDIA) Team. Epidemiology, 11: 450-456.

Wyon, D. P., (1975) The mental performance of subjects clothed for comfort at two different air temperatures. Ergonomics, 18: 359-374.

Wyon, D. P., Andersen, I., and Lundqvist, G. R., (1979) The effects of moderate heat stress on mental performance. Scand J Work Environ Health, 5: 352-361.

Wyon, D. P., (1993) Healthy buildings and their impact on productivity. Indoor Air '93: Proceedings of the 6th International Conference on Indoor Air Quality and Climate, 6: 313.

Wyon, D. P., (1996) Indoor environmental effects on productivity. IAQ '96: Paths to Better Building Environments, 1: 5-15.

Wyon, D. P., (2000) Thermal effects on performance. In Spengler, J., Samet, J. M., and McCarthy, J. F. (eds.), Indoor Air Quality Handbook. New York: McGraw-Hill, 16.1116.16 .

Ziomeck, R. and Schoenberger, W., (1983) The relationship of Title I student achievement to program and school attendance. The Elementary School Journal, 84: 232-240.

Zock, J. P., Kogevinas, M., Sunyer, J., Almar, E., Muniozguren, N., Payo, F., Sanchez, J. L., and Anto, J. M., (2001) Asthma risk, cleaning activities and use of specific cleaning products among Spanish indoor cleaners. Scand J Work Environ Health, 27: 76-81 